American Journal of Infectious Diseases 7 (4): 107-109, 2011

ISSN 1553-6203

(C) 2011 Science Publications

\title{
Nasal Myiasis Caused by Cochliomyia Hominivorax in the United States: A Case Report
}

\author{
${ }^{1}$ Ryan Tai, ${ }^{1}$ Michael A. Marsh, ${ }^{1}$ Ryan Rao, \\ ${ }^{1}$ Peter C. Kurniali, ${ }^{2}$ Ernest DiNino and ${ }^{2}$ Joseph V. Meharg \\ ${ }^{1}$ Department of Internal Medicine, \\ Roger Williams Medical Center, \\ Boston University School of Medicine, Providence, Rhode Island \\ ${ }^{2}$ Department of Internal Medicine, Division of Pulmonary and Critical Care, \\ Roger Williams Medical Center, \\ Boston University School of Medicine, Providence, Rhode Island
}

\begin{abstract}
Cases of human myiasis caused by Cochliomyia hominivorax are typically reported in Central and South America. We report a case of nasal myiasis, which manifested in a hospitalized patient in the United States who did not have a recent travel history. The larvae were discovered in the patient's nares on the fifth day of hospitalization. The patient was successfully treated with Ivermectin over two days.
\end{abstract}

Key words: Nasal myiasis, Cochliomyia hominivorax, screw-worm, ivermectin

\section{INTRODUCTION}

Myiasis is defined as the consumption of tissues, fluids, or ingested foods of vertebrates by the larvae of organisms of the order Diptera (Hall and Wall, 1995). While myiasis typically involves infestation of dead tissues, Cochliomyia hominivorax, the New World screw-worm fly, is an obligate parasite that preferentially consumes the living tissue of warm-blooded mammals. Typical infestations occur in livestock and manifest as weight loss (Madeira et al., 1998).

Cases of Cochliomyia hominivorax infections in humans are less common and occur in patients with the following risk factors: open wounds, poor hygiene, low educational level, alcoholism, immobility and physical or mental disability (Batista-Da-Silva et al., 2011).

Case: The patient is a 70 year-old-man with a past medical history of diabetes mellitus, hypertension, Chronic Obstructive Pulmonary Disease (COPD) and untreated Obstructive Sleep Apnea (OSA). He was admitted to the hospital for shortness of breath and intermittent hyper-somnolence. He was subsequently intubated due to hypercarbic respiratory failure and was transferred to the Intensive Care Unit.

On day five of hospitalization, a nurse observed white thread-like organisms emerging from the patient's nasal cavity and entering the patient's mouth Fig. 1. The same organisms were found in the suction tubing. Nasal swab was performed and a dozen larvae were collected and sent to microbiology. Upon visualization with direct light, the organisms displayed photophobia by migrating rapidly back into the nasal cavity. The patient's nares were flushed with mineral oil and he received Ivermectin $200 \mathrm{mcg} \mathrm{kg}^{-1}$ per day for two days.
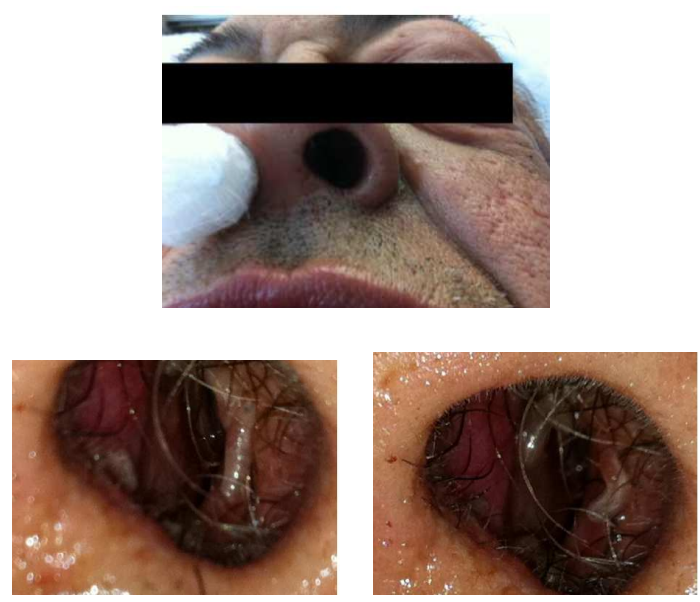

Fig. 1: Maggots visualized in patient's nasal cavity

Corresponding Author: Ryan Tai, Department of Internal Medicine, Roger Williams Medical Center, Boston University School of Medicine, Providence, Rhode Island 02908 
The following day, maxillofacial and head CT showed layering of fluid and mucosal thickening of the maxillary, ethmoid and sphenoid sinuses without evidence of deep tissue involvement. Augmentin $875 \mathrm{mg}$ twice a day was initiated.

Based on morphology, specimens sent to microbiology the previous night were confirmed to be Cochliomyia hominivorax Fig. 2 and 3. The case was reported to the hospital Infection Control Department and the State Department of Health. On hospital day 8 , the patient was evaluated by fiberoptic nasal endoscopy, which revealed diffusely hyperemic nasal mucosa with old blood in the posterior nasopharynx, but without significant ulceration or necrosis. No larvae were seen.

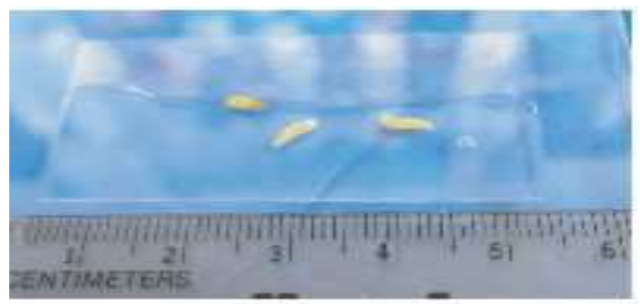

Fig. 2: Gross morphology of Cochliomyia hominivorax larvae

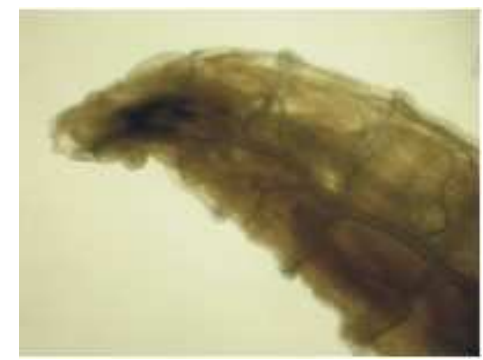

(A)

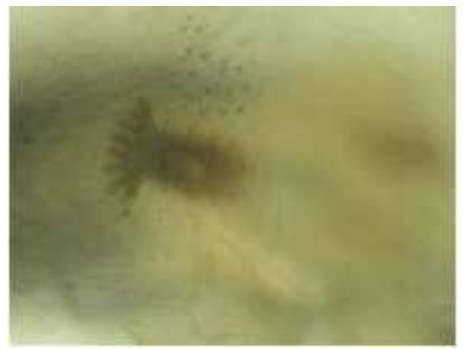

(B)

Fig. 3: (A) Microbiological analysis of Cochliomyia hominivorax under the microscope $(400 \times)$. Posterior spiracles and posterior surface of the last segment (B) Open peritreme of posterior spiracle
Prior to its eradication from the United States in 1982, Cochliomyia hominivorax caused significant economic losses to the livestock industry (Wyss, 2000). Detection of Cochliomyia hominivorax on livestock in the United States is reportable to the State Veterinarian USDA Animal and Plant Health Inspection Service 2011. Since 1982, there have been several case reports of myiasis involving Cochliomyia hominivorax in imported animals from endemic countries (APHIS, 2007).

Cases of screw-worm myiasis in humans continue to be reported in endemic countries, especially in Central and South America (Powers et al., 1996; Gomez et al., 2003; Duque and Ardila, 2011; Coronado and Kowalski, 2009). Human myiasis has also been reported in individuals who have traveled to these countries (Mehr et al., 1991). The larvae can cause ocular (Khurana et al., 2010), oral (Junior et al., 2010), umbilical (Duro et al., 2007), subcutaneous (Trombetta et al., 2009) and nasal (Couppie et al., 2005) infections. The Cochliomyia hominivorax adult fly form lays eggs on the edges of wounds and necrotic tissue; the larval form consumes living tissue resulting in destruction of soft tissues, including cartilage (Hall and Wall, 1995; Gomez et al., 2003).

The patient is originally from Puerto Rico and denied recent travel outside the United States. Friends from South America, who came in contact with the patient several days prior to hospitalization, are a possible source of the parasite. Typically, within 1224 hours of the female fly depositing eggs, larvae emerge and feed on the host (IOEIC, 2008). After five to nine days, the larvae mature and abandon the host to pupate in soil (IOEIC, 2008). Manifestation of the larvae outside the patient's nares on the fifth day of hospitalization suggested that the infestation most likely occurred outside the hospital and the patient's altered mental status at home may have predisposed him to infestation.

Typically, myiasis is treated with direct removal of larvae, systemic treatment with Ivermectin $150-200 \mathrm{mcg}$ $\mathrm{kg}^{-1}$ over two days and topical adjuvant antibiotics (Rossi-Schneider et al., 2007; Maheshwari and Naidu, 2010). Application of ether, chloroform, or oil may also be used to coax the larvae out of the subcutaneous tissue, (Maheshwari and Naidu, 2010) but the utility of this approach is unclear (Shinohara et al., 2004). With nasal myiasis, endoscopy is often utilized to evaluate the nasal cavity and extract larvae under direct visualization (Tsang and Lee, 2009). Maxillofacial CT scans are often useful in nasal myiasis to determine the extent of soft tissue or bony destruction (Lee et al., 2011).

To our knowledge, this is the first reported case of human nasal myiasis by Cochliomyia hominivorax in 
the United States, since its eradication in 1982. Treatment with Ivermectin appears to have been effective as no larvae were found after 48 hours of treatment initiation and the patient remained without evidence of infection two weeks later.

With treatment of COPD and OSA, the patient improved and was discharged to a rehabilitation facility 21 days post admission.

\section{CONCLUSION}

With globalization and facillitated travel, remergence of previously eradicated organisms, such as Cochliomyia hominivorax, may be more likely to occur. We report a case of nasal myiasis caused by Cochliomyia hominivorax, which was evaluated with head and maxillofacial CT and nasal endoscopy and successfully treated with a two day course of Ivermectin.

\section{REFERENCES}

APHIS, 2007. 2006 United States Animal Health Report. 1st Edn., Animal and Plant Health Inspection Service, USA., pp: 178.

Batista-Da-Silva, J.A., G.E. Moya-Borja and M.M.C. Queiroz, 2011. Factors of susceptibility of human myiasis caused by the New World screw-worm, Cochliomyia hominivorax in Sao Goncalo, Rio de Janeiro, Brazil. J. Insect Sci., 11: 1-7.

Coronado, A. and A. Kowalski, 2009. Current status of the New World screwworm Cochliomyia hominivorax in Venezuela. Med. Vet. Entomol., 23: 106-110. PMID: 19335837

Couppie, P., M. Roussel, P. Rabarison, M.J. Sockeel and D. Sainte-Marie et al., 2005. Nosocomial nasal myiasis owing to Cochliomyia hominivorax: A case in French Guiana. Int. J. Dermatol., 44: 302303. PMID: 15811082

Duque, F.L. and C.M. Ardila, 2011. Oral myiasis caused by the screwworm Cochliomyia hominivorax treated with subcutaneous ivermectin and creolin: Report of six cases after trauma. Dent. Traumatol., 27: 404-407. PMID: 21535400.

Duro, E.A., J.C. Mariouis and P.R. Mulieri, 2007. Umbilical myiasis in a human newborn. J. Perinatol., 27: 250-251. DOI: 10.1038/sj.jp.7211654

Gomez, R.S., P.F. Perdigao, F.J.G.S. Pimenta, A.C.R. Leite and J.C.T.D. Lacerda et al., 2003. Oral myiasis by screwworm Cochliomyia hominivorax. Br. J. Oral. Maxillofac. Surg., 41: 115-116. DOI: 10.1016/S0266-4356(02)00302-9
Hall, M. and R. Wall, 1995. Myiasis of humans and domestic animals. Adv. Paristol., 35: 257-334. DOI: 10.1016/S0065-308X(08)60073-1

IOEIC, 2008. Manual of Diagnostic Tests and Vaccines for Terrestrial Animals: Mammals, Birds and Bees. 1st Edn., Office International Des Epizooties, Paris, pp: 1343.

Junior, S.M.L., L. Asprino, A.P. Prado, R.W. Moreira and M.D. Moraes, 2010. Oral myiasis caused by Cochliomyia hominivorax treated nonsurgically with nitrofurazone: Report of 2 cases. Oral Surg. Oral Med. Oral Pathol. Oral Radiol. Endod., 109: e70-e73. PMID: 20219589

Khurana, S., M. Biswal, H.S. Bhatti, S.S. Pandav and A. Gupta et al., 2010. Ophthalmomyiasis: Three cases from North India. Indian J. Med. Microbiol., 28: 257-261. PMID: 20644320

Lee, Y.T., T.L. Chen, Y.C. Lin, C.P. Fung and W.L. Cho, 2011. Nosocomial nasal myiasis in an intubated patient. J. Chin. Med. Assoc., 74: 369371. DOI: 10.1016/j.jcma.2011.06.001

Madeira, N.G., A.F.T. Amarante and C.R. Padovani, 1998. Effect of management practices on screwworm among sheep in Sao Paulo state, Brazil. Trop. Anim. Health Prod., 30: 149-157. DOI: 10.1023/A:1005055518916

Maheshwari, V.J. and S.G. Naidu, 2010. Oral myiasis caused by Chrysomya bezziana: A case report. People's J. Sci. Res., 3: 25-26.

Mehr, Z., N.R. Powers and K.A. Konkol, 1991. Myiasis in a wounded soldier returning from Panama. J. Med. Entomol., 28: 553-554. PMID: 1941919

Powers, N.R., M.L. Yorgensen, P.D. Rumm and W. Souffront, 1996. Myiasis in humans: An overview and a report of two cases in the Republic of Panama. Mil Med., 161: 495-497. PMID: 8772307

Rossi-Schneider, T., K. Cherubini, L.S. Yurgel, F. Salum and M.A. Figueiredo, 2007. Oral myiasis: A case report. J Oral Sci., 49: 85-88.

Shinohara, E.H., M.Z. Martini, H.G.D.O. Neto and A. Takahashi, 2004. Oral myiasis treated with ivermectin: Case report. Braz. Dent. J., 15: 79-81.

Trombetta, L., A. Oliva, V. Galache, J. Bava and A. Troncoso, 2009. Cutaneous myiasis due to Cochliomyia hominivorax in a drug user. J. Infect. Dev. Ctries, 3: 873-876. PMID: 20061685

Tsang, W.S. and D.L. Lee, 2009. Nasal myiasis: The role of endoscopy. Ear. Nose Throat J., 88: 12501251. PMID: 20013672

Wyss, J.H., 2000. Screwworm eradication in the Americas. Ann. N. Y. Acad. Sci., 916: 186-193. PMID: 11193620 